by the hospice, including a $167 \%$ increase in neonatal referrals for use of the bereavement suite. The value of hospice services has been clearly acknowledged by tertiary centres, along with very positive feedback direct from families.

'We miss Emmalyn every day but we are so thankful that Claire House helped us create such happy memories that we can cherish forever.' Victoria, mum of Emmalyn who was diagnosed with Trisomy 18 and lived for 26 days.

Conclusion Clearly the children's hospice has a definitive role within PPC. The presence of hospice staff within tertiary centres has enabled good palliative care planning with all relevant professionals of the multi-disciplinary team. Thus, providing seamless and compassionate support for families, with a choice of their preferred place of care. We aspire to develop stronger partnerships in the future, with the development of a jointly commissioned post (hospital/hospice) to lead PPC across Cheshire and Merseyside.

\section{P-183 COLLABORATING WITH LOCAL SERVICES TO IMPROVE ACCESS TO EQUIPMENT TO SUPPORT PREFERRED PLACE OF CARE AND DEATH}

Liz Strachan. Princess Alice Hospice, Esher, UK

\subsection{6/bmjspcare-2017-hospice.208}

Background To enable patients to safely remain in their preferred place of care (PPC) or death (PPD) and to maximise their independence within the limitations of their illness, specialist equipment may be needed.

Historically, hospice therapists had limited access to equipment which had been either bought by the hospice, or donated. To secure other equipment, lengthy reports were completed by hospice occupational therapists (OT) and then sent to the OT within one of 12 social services locality teams. They, in turn, ordered the equipment through Community Equipment Services (CES) on the hospice therapist's behalf. This sometimes led to confusion and delays of equipment being delivered, resulting in patients not fulfilling their PPC/ PPD.

Aim To have the means to provide equipment to patients in a timely fashion to support PPC/PPD.

Results Following three years of collaborative working with the Clinical Lead for Equipment, locality teams and Integrated Community Equipment Services (CES) across Surrey, a peripheral store is now on site at the hospice. This allows instant access to a range of equipment which can be immediately supplied to patients. To facilitate this, each OT and physiotherapist now has an individual PIN number. This new process increases the possibility of achieving a safe environment for PPC and PPD.

Conclusion This has led to the following benefits:

- Enabled more patients to achieve their PPC/PPD

- Supported patients to maximise their independence in their own environment

- Reduced administrative time for hospice and social services therapists

- Freed up time for increased face-to-face interventions

- Reduced delivery costs for social services locality teams

- Increased job satisfaction for hospice therapists.
Future development of this project will include:

- Negotiating with social service teams that are currently not involved in this collaborative working

- To resolve challenges in relation to Continuing Health Care funded provision of equipment.

\section{P-184 DELIVERING AN INTEGRATED END OF LIFE CARE SERVICE - IS IT SUSTAINABLE SIX YEARS ON?}

Kate Heaps, Alison McCarthy, Jonathan Devlin. Greenwich and Bexley Community Hospice, Abbey Wood, UK

\subsection{6/bmjspcare-2017-hospice.209}

Background The Greenwich Care Partnership (GCP) was born out of the Marie Curie Delivering Choice Programme (DCP). Three service providers developed the service, with the hospice as prime contractor and two sub-contracted partners. The service has been in operation since 2011.

Service Aims

- To increase the number of people who are able to die in their place of choice

- To ensure appropriate health and personal care services

- To provide family support.

Service Approach The service operates alongside core services to support high quality care across four areas:

- Care co-ordination

- Rapid Response Service - Out of Hours

- Personal care and support

- Night care.

Elements are provided by different providers working together to ensure seamless care 24/7.

The following data will be reported:

- Activity data collected over the duration of the project

- HR information regarding staff retention and staff satisfaction ratings

- VOICES feedback.

Service outcomes:

- Sustained increase in home and hospice deaths

- Maintained reduction in hospital admissions, length of stay and deaths

- Low staff turnover and high job satisfaction for carers in service

- Catalysing further integration and service innovation

- High patient and carer satisfaction.

Challenges:

- 'Flat' funding with growth in service activity

- Organisational change at CCG and continuity of communication with partner organisations

- Continued lack of GP engagement in end of life care.

Conclusion The service continues to deliver its intended outcomes and has acted as a catalyst for further innovation and integration. Despite a number of challenges throughout the project, the service remains sustainable and is a key part of the hospice service. 